\title{
LOS CASTILLOS MUSULMANES DEL NORTE DE LA PROVINCIA DE ALICANTE
}

\author{
Pierre Guichard
}

Dos libros recientes han llamado la atención sobre los castillos alicantinos. En primer lugar el inventario histórico-turístico de Francisco G. SEIJO ALONSO, Castillos del país valenciano, primera parte (Alicante, 1978), y luego el estudio de caracter más netamente arqueológico y erudito de Rafael AZUAR RUIZ, Castellología medieval alicantina: Area meridional (Alicante, 1981). En varios lugares de la zona, el estudio de los castillos está despertando en la actualidad un nuevo interés por parte de los in: vestigadores o grupos interesados en la conservación y estudio de los restos del pasado (1). El propósito de este artículo es contribuir a un mejor conocimiento de la realidad «castellológica» provincial, con la aportación de algunos datos inéditos y la inserción de los castillos alicantinos dentro de la problemática general de los castillos levan-

(1) Agradezco a Ricard BAÑO i ARMIÑANA y José TORRO ABAD en Alcoy, y a Enrique CATALA y Pere FERRER en Cocentaina, las valiosas informaciones que me han proporcionado. Quiero destacar particularmente la generosa ayuda prestada por José María SE. GURA MARTI, en el museo de Alcoy, al facilitarme varios planos y estudios realizados por él y no publicados todavía sobre los castillos medievales de la zona. Las informaciones obte. nidas e integradas a este artículo constan en su debido lugar. Debo a mi amigo André BAZZANA la fotografía aérea que me ha permitido realizar el dibujo del Castillo de Pego. 
tinos. Limitaremos la investigación a la zona septentrional de la provincia, que no ha sido estudiada en el mencionado libro de Azuar Ruiz, y debe su unidad histórica al hecho de haber sido integrada dese mediados del siglo XIII a la corona aragonesa, mientras la parte meridional, con la propia capital provincial, no fue unida a los dominios aragoneses hasta finales del mismo siglo. Estas circunstancias favorecen la investigación histórica sobre los castillos del norte, pues se puede aprovechar la importante documentación del siglo XIII en la Corona de Aragón, que contrasta con la relativa pobreza arhivistica de la zona que el tratado de Almizra de 1244 dejó a la Corona de Castilla.

Los castillos alicantinos son, en su gran mayoría, de origen musulmán. Solamente unos pocos fueron edificados en época posterior a la conquista cristiana, como el "palacete» de Cox y, en la zona que nos ocupa, los pequeños castillos señoriales de Penella, Orba y, con toda probabilidad, Barchell y Forna (2). En todos aquellos casos, tanto la documentación como los detalles de la construcción y la misma estructura general de la fortificación denotan una fecha tardía, aunque en algún caso el castillo cristiano puede haber sido edificado sobre los restos de una torre, alquería, o pequeño lugar fortificado musulmán. En Orba, por ejemplo, hay abundante cerámica altomedieval alrededor del castillo cristiano. En Barchell, se han encontrado cerámicas musulmanas, que atestiguan la existencia de alguna alquería, a poca distancia de la mansión fortificada de tipo señorial cristiano (3). El castillo de Benifallim puede tener también como origen una torre de alquería, aprovechada luego por los señores cristianos del lugar. Pero en la documentación del siglo XIII, este tiene claramente la categoría de una simple alquería, que pertenece al término del castrum de Penáguila (4).

(2) AZUAR RUIZ, Castellología medieval alicantina, pp. 99-106 sobre Cox; sobre los documentos relativos a la construcción de Penella en 1271 (Archivo de la Corona de Aragón, Reg. Cancilleria $n^{\circ} 205$, fol. 150 , r.v.), y Orba en 1289 (id., $n^{\circ} 78$, fol. 32), vease mi breve estudio sobre "Châteaux chrétiens du royaume de Valence», en: Châteaux et peuplements en Europe occidentale du $X^{e}$ au XVIII siècle, Premières journées internationales d'Histoire du Centre culturel de l'abbaye de Flaran, 20-22 sept. 1979, Auch, 1980, pp. 197. 202.

(3) Información proporcionada por J.M. SEGURA MARTI y J. TORRO ABAD.

(4) Archivo de la Corona de Aragón, Reg. de Cancilleria n ${ }^{\circ} 10$, fol. 61 v. Documento de donación de la alquería de Benifallim, a 28 de abril de 1258 , en el que se menciona una fortalicia. 
La definición de un lugar como castrum o alquería y la distin ción entre ambas realidades en la documentación de los años inmediatamente posteriores a la conquista cristiana me parece muy importante y estrechamente relacionada con las estructuras políticosociales de la época musulmana. Una buena comprensión de dichas estructuras permite, a mi parecer, una interpretación más correcta de los castillos musulmanes, y contribuye mucho a su estudio. Cabe indicar en primer lugar que el modo de organización de la sociedad musulmana valenciana en vísperas de la "Reconquista» era muy distinto al de la sociedad cristiana muy dominada por las relaciones de tipo señorial o feudal. Percibimos, a través de la documentación escrita, dos realidades sociopolíticas antagonistas: las comunidades rurales por una parte, y el Estado islámico por otra (5). El peso social de la clase de los alcaides, o tenentes de castillos es difícil de valorar exactamente a falta de una cantidad suficiente de fuentes, pero no parece que hayan ocupado en la sociedad un puesto comparable al de los señores feudales o magnates en la sociedad y las cons. trucciones políticas cristianas (6). A mi parecer, los historiadores no se han preocupado bastante por establecer los rasgos que diferenciaban ambas sociedades, e incluso los estudios más recientes adolecen de una visión clara del problema (7).

La consecuencia de esta confusión entre ambas épocas es que los castillos musulmanes han tendido a ser interpretados dentro de un contexto semejante al de la sociedad cristiana, y no referidos a la realidad socio:política musulmana. En su introducción al estudio de Azuar Ruiz sobre los castillos de la parte meridional de la provincia de Alicante, Enrique Llobregat hace al respecto una advertencia o crítica que me parece muy pertinente: «Tampoco me con-

(5) Sobre esto, remito a los capítulos sobre la sociedad musulmana valenciana que he re. dactado para la reciente historia de la región valenciana publicada bajo el título de Nuestra Historia, vol. II y III, Valencia, 1980.

(6) Véase el trabajo indicado en la nota precedente, y: P. GUICHARD, «Le problème de l'existence de structures de type 'féodal' dans la société d'al-Andalus (l'exemple de la région valencienne)», en: Structures féodales et féodalisme dans l'Occident méditerranéen, Ecole française de Rome, 1980, pp. 699-728.

(7) Ni siquiera los estudios del P. R.I. BURNS, dedicados a la sociedad mudejar valenciana del siglo XIII, aclaran correctamente el problema. Es verdad que van dedicados prin cipalmente al estudio de la sociedad musulmana dentro de una perspectiva demasiado conti nuista que, a mi parecer, le impide valorar la importancia de los cambios sociales que se produjeron al pasar de una época a la otra. 
vence, dice, el empleo de la expresión acuñada "torre del homenaje» o «donjon»... porque prejuzga un tipo de relación económicosocial que no es en absoluto seguro que llegara a darse entre las comunidades islámicas habitantes de la zona estudiada». Hay que sacar todas las consecuencias de esta observación. En una sociedad de tipo señorial o feudal, el donjon es un elemento fundamental del castillo, en cuanto instrumento de la dominación militar del «señor» y de sus milites sobre los trabajadores dependientes. En una sociedad que no conoce este tipo de relaciones sociales, en cambio, se puede pensar a priori que la fortificación no va a organizarse alrededor de tal «torre del homenaje», que no tienen ninguna razón

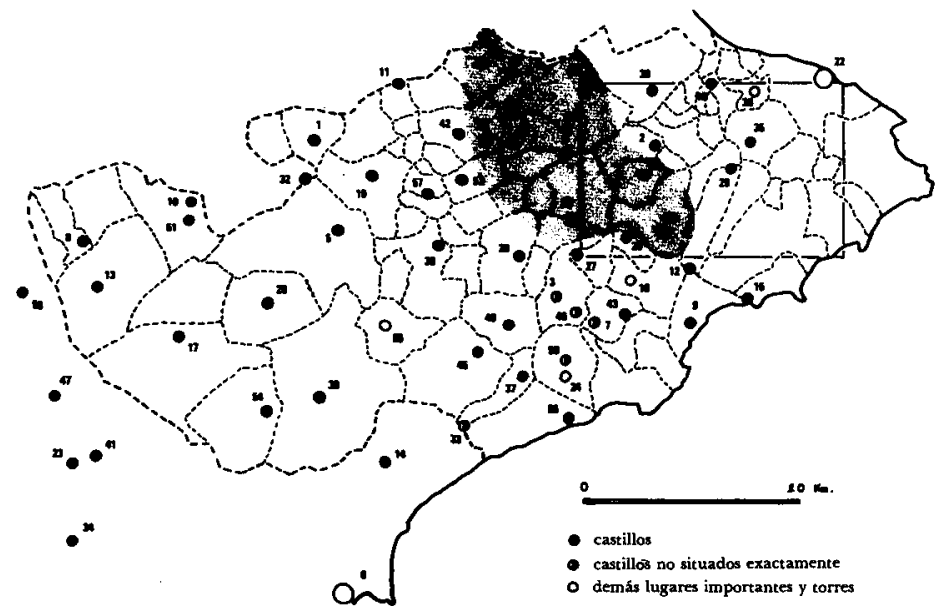

1. Castillos musulmanes del norte de la provincia de Alicante.

Se han indicado todos los castillos (husun o castra) musulmanes, y parte de los demas lu. gares fortificados. El marco rectangular señala la zona cubierta por el mapa catastral 622 (hoja Benisa). La zona gris incluye los castillos mencionados en el pacto de Alcalá de 1244.

1: Agres;- 2: Alaguar;- 3: Alarch;- 4: Alcalá;-5: Alcoy;- 6: Alicante;- 7: Aljubea;- 8: Almizra;-9: Altea;- 10: Bañeres;- 11: Benicadell;- 12: Bernia;- 13: Biar;- 14: Busot;- 15: Calpe;- 16: Callosa;- 17: Castalla;- 18: Castell de Castells;- 19: Cocentaina;- 20: Confrides; 21 : Cheroles;- 22: Denia;- 23: Elda;- 24: Finestrat;- 25: Gallinera;- 26: Gartx;- 27: Guadalest;28: Ibi;- 29: Jalón;- 30: Jijona;- 31: Margarida;- 32: Mariola; 33: la Mola (d'Agues);- 34: la Mola de Novelda;- 35: Olocaiba;- 36: Ondara;- 37: Orcheta;- 38: Pego;- 39: Penáguila;- 40: Perpunchent;- 41: Petrel;- 42: Planes;- 43: Polop;- 44: Pop;- 45: Relleu:- 46: Sanchet;- 47: Sax;-48: Segarria;- 49: Sella;- 50: Serra (de Finestrat);- 51 : Serrella;- 52: Seta;-53: Tárbe na;- 54: Tibi;- 55: Torremanzanas;- 56: Torres;- 57: Travadell;- 58: Villena. 
de ser. Este razonamiento puede parecer algo esquemático y demasiado simplificador de unas realidades a veces más complejas, pero nos ayuda a adoptar una visión crítica de la estructura de los castillos musulmanes, y a reflexionar sobre las relaciones de dicha estructura con el modo de organización social.

De hecho, en muchos de los castillos de la zona estudiada, no hay ninguna torre central. Si tomamos como ejemplo los castillos situados en la zona cubierta por la hoja BENISA ( $\left.\mathrm{n}^{\circ}, 822\right)$ del mapa al $1 / 50.000$, comprobamos que no se encuentran vestigios de tales torres en Pego, ni en Segarria (del término de Benimelí), ni en Laguar (término de Vall de Laguart), ni en Pop (término de Murla), ni en Tárbena, todos castillos que parecen haber sido poco modificados después de la conquista cristiana. En Jalón, solo existen unos pobres restos de edificaciones cuya naturaleza exacta es difícil determinar. En Gartx (término de Bolulla), hay en la parte más alta del castillo como un reducto central defendido por dos torres redondas bastante pequeñas, que incluye en su interior otra torre de la misma forma, pero más importante (de alrededor de 6 $50 \mathrm{~m}$. de diámetro), que puede haber servido de habitación, pero cuyo papel defensivo parece escaso. El único castillo cuyo elemento más importante es una torre, sin duda muy antigua pues aparece ya en la documentación del siglo XIII, y tiene algún parecido con el clásico donjon (aunque sus dimensiones son muy modestas), es el castillo de Olocaiba, en término de Pedreguer (8). Parecidos hechos se observarían en toda la zona septentrional, particularmente la que linda con la provincia de Valencia, donde las torres del homenaje más importantes son sin duda de construcción cristiana, como en Cocentaina y Perpuchent (del término de Lorcha) (9).

La estructura de los castillos situados en la zona fronteriza del tratado de Almizra parece algo más compleja. En su estado actual,

(8) «Turrem et alcherias de Olocayba y Perer (Pedreguer)»... «Alcherias predictas cum fortitudine earum sive turri»: Archivo de la Corona de Aragón, Reg. de Cancilleria ${ }^{\circ} 21$, fol. $7 \mathrm{r}$., documento del 8 de agosto de 1271 . Dicha "torre», muy derruida, existe todavia en el lugar llamado Castellet del Ocaibe, del término de Pedreguer. Se trata de un edificio cuadrado bastante pequeño (menos de $5 \mathrm{~m}$. de lado), establecido en una cresta rocosa que domina un rellano de la montaña del Ocaibe, donde una gran cisterna y abundantes restos cerámicos revelan la existencia de un antiguo poblado.

(9) Sobre el castillo de Perpunchent, estudio monográfico en prensa por A. BAZZANA, P. GUICHARD y J.M. SEGURA MARTI, en Mélanges de la Casa de Velázquez, XVII, 1981. 


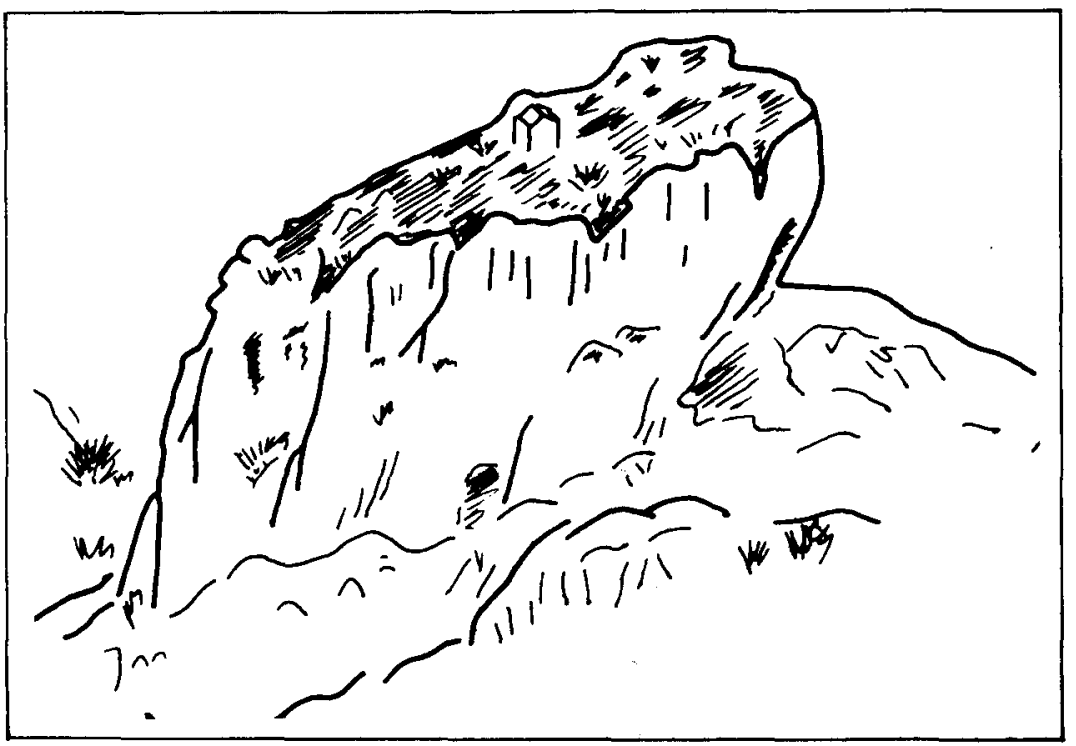

2. El castell de Margarida.

Interesante ejemplo de hisn constituido por una peña-refugio, que no necesita defensas artificiales. El plano dibujado por J. $\mathbf{M}^{\mathbf{a}}$ Segura Martî y E. Cortell Pérez indica como dimen. siones de la meseta superior unos 80 por 35 metros. la única construcción es un edificio casi cuadrado de alrededor de $5 \mathrm{~m}$. de lado. que parece de época cristiano.

están caracterizados en primer lugar por sus grandes y vistosas «torres del homenaje», a las que deben su aspecto particularmente pintoresco. Esta peculiaridad les hace semejantes a los del lado castellano de la antigua frontera, y forman con ellos un grupo distinto, en el que la primitiva organización de épocá islámica ha sido muy modificada por las reformas posteriores, debidas precisamente a su particular situación fronteriza (10). Por ello, dejando a un lado las fortalezas de Bañeres, Biar, Castalla, Tibi, centraremos el estudio sobre los castillos de la zona interior, en los que la estructura primi-

(10) Los castillos de Bañeres, Biar, Jijona, la Mola de Novelda, Sax y Villena, están incluidos en el estudio de Azuar Ruiz. Un buen ejemplo de castillo totalmente transformado después de la conquista cristiana, con edificación de una gran torre del homenaje, es Sax (Castellologia alicantina, pp. 169-176; véase también el esquema comparado de las estructuras musulmana y cristiana del mismo castillo, muy sugestivo, en André BAZZANA, "Eléments d’archéologie musulmane dans al-Andalus: caractères spécifiques de l'architecture militaire arabe de la région valencienne», Al-Qántara, vol. 1, 1980, p. 353). 
tiva queda mucho más visible.

No pretendo que las fortalezas musulmanas no fueron nunca organizadas alrededor de una torre principal semejante al donjon de los castillos «feudales» occidentales (11). Me parece interesante apuntar, sin embargo, que cuando uno de los castillos de la zona que estudiamos estaba constituido principalmente por una torre, como en el caso de Olocaiba donde tal torre es atestiguada arqueológicamente, la documentación escrita revela ciertas dudas en cuanto a la categoría de castrum de dicha fortificación (12). Idénticas dudas aparecen en cuanto al castillo de Altea (13).

Generalmente, las simples torres aisladas parecen haber formado el elemento defensivo característico de las alquerías fortificadas (14), sin duda las más importantes, o las que se encontraban situado demasiado lejos de los verdaderos castillos, los que los textos árabes denominan husun (plural de hisn), y los latinos castra.

La pobreza de las fuentes árabes no permite un conocimiento directo de la geografía de los husun. La lista más interesante es la que proporciona el famoso «Pacto de Alcalá», firmado entre Jaime I y el caudillo musulmân al-Azraq en 1244 ó 1245, en el que aparecen los ocho husun de Barbunyan (Perpunchent), Galinar (Gallinera), al-Qal'a (Alcala), Bûb (Pop), Margalîta (Margarita), Tarbana (Tárbena), Qastâl (Castell de Castells) y Ŷurûlas, todos perfectamente identificables, con la única excepción del último cu-

(11) Según el estudio de Azuar Ruiz, las torres del homenaje de los castillos de Biar y Ville. na serian de construcción almohade. Los argumentos aducidos no carecen de fuerza. Hay que notar, sin embargo, que se trata de fortalezas más importantes que la mayoría de los simples castillos rurales de los que tratamos en esta exposición. En cuanto a Bañeres, podría tratarse de un castillo señorial edificado alrededor de una antigua torre de alquería.

(12) Véase la nota 8: El documento citado habla de torre y de fortitudo, dos palabras que denotan cierta ambigüedad en la definición del lugar, llamado castrum en otros documen tos.

(13) Archivo de la Corona de Aragón, Reg. Cancilleria ${ }^{\circ} 12$, fol. 119 , documento del 30 de septiembre de 1263, que menciona la torre de Altea, así como otro ducmento del 29 de junio de 1272 (Reg. $n^{\circ} 21$, fol. 43 v.). Quizás esta fortificación se encontrase en el lugar lla. mado actualmente Altea la Vieja.

(14) Tales torres parecen haber existido en un buen número de alquerias o poblaciones ya bastante importantes, que no llegaban a la categoría de castrum çntro de término, como Beniarrés, Almudaina de Planes, Negret (cerca de Benejama), Callosa. Onil, etc... Sobre es. te tipo de fortificación, véase: A. BAZZANA y P. GUICHARD, "Les tours de défense de la Huerta de Valence au XIII' siècle», Mélanges de la Casa de Velázquez, XIV. 1978, pp. 73. 105. 
ya localización plantea un problema (15). Todos estos castillos corresponden a lugares naturalmente defendidos tanto por su altura como por su situación topográfica. Entre los más espectaculares figura el "castellet de Margarita", a poca distancia del actual poblado de este nombre, constituido por una meseta rocosa que protege por todas partes un impresionante e inaccesible acantilado (16). En Gallinera, Alcalá, Tárbena, Castell, Perpunchent, construcciones defensivas más o menos importantes completan y refuerzan las condiciones naturales. Lógicamente, los acondicionamientos defensivos son tanto más fuertes cuanto menos defendido esta naturalmente el sitio. Generalmente, se trata de un espolón rocoso protegido en un lado por un acantilado, y por las demás partes por un muro de recinto, a veces un doble muro como en Perpunchent.

Todos estos castillos aparecen como castra en la documentación cristiana posterior a la conquista, y nunca se confunden con el otro tipo de establecimiento humano que los cristianos encontraron en el país, la alquería. Tanto en el Pacto de Alcalá como en los documentos cristianos, aparece claramente una organización territorial fundamentada en la asociación de un castillo con las alquerías de su término, constituyendo el conjunto la célula básica de la vida social y política en la organización de la época musulmana. Las fuentes cristianas dan a esta unidad socio-política el nombre de aljama, que traduce el árabe al-ŷamâ'a, palabra que designa una reunión o grupo de hombres, pero en este contexto tiene también el significado de consejo, y alude al consejo de los vells o ancianos y notables que regían estas pequeñas comunidades rurales. Generalmente, cada término castral formaba como un pequeño distrito definido muchas veces en primer lugar por la geografia física (generalmente un «valle» o sección de valle), que comprendía, además del castillo, varias alquerías (digamos entre cinco y quince), es decir pequeños barrios o poblados rurales, que no correspondían a granjas aisladas sino a grupos de unas cuantas casas y familias, muchos de los cuales

(15) F. de P. MOMBlanCH, Al Azraq, capitán de moros, Valencia, 1977, da un estudio del texto. acompañado de la reproducción del documento original del Archivo de la Corona de Aragón. Sobre el castillo de Ŷurúlas, véase la noticia que le va dedicada, al final del artículo.

(16) Este castillo ha sido estudiado por J.M. SEGURA MARTI, y los planos y el material recogido se encuentran en el museo de Alcoy. 


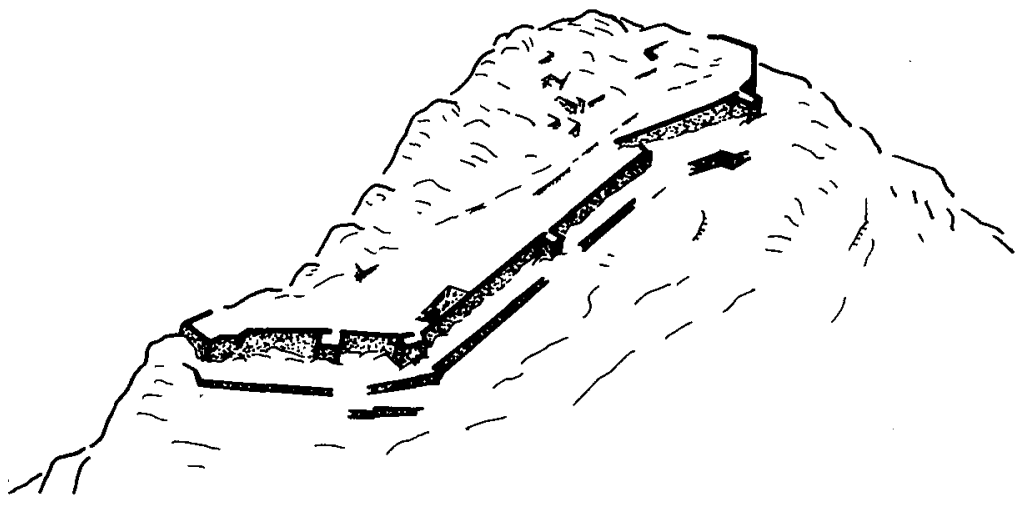

3. El castillo de Pego.

A la misma escala aproximadamente que el dibujo anterior (mide unos 160 por $35 \mathrm{~m}$.). Se observará la notable «horizotalidad» de la estructura, el doble recinto defensivo, y los escasos restos de construcciones no defensivas en la parte rocosa interior (dibujo según fotografía aérea Andrê Bazzana/Casa de Velázquez).

llevaban topónimos gentilicios en Beni-, que indican que se trataba de unidades parentales de tipo «clánico». Ya he insistito varias veces sobre este esquema de organizción de la población tan característico de la zona valenciana, que se observa con una particular claridad en la zona que estamos estudiando, y que hay que relacionar con la existencia de fuertes comunidades rurales no «señorializadas» (17).

El castillo se nos aparece como el centro «estructurador» del territorio ocupado por cada aljama. Castillo y término llevan un mismo nombre, que es generalmente un topónimo prearabe, lo que hce pensar que estas unidades castrales se habían constituido en fecha bastante temprana, anterior a la arabización lingüística que, en esta región, ha influido mucho sobre la toponimia. La estructura defensiva mas característica se reduce a un amplio recinto, que prote-

(17) Remito otra vez a mi estudio en Nuestra Historia (véase en particular el vol. II, pp. 273-277). 
ge un área de refugio bastante grande para acoger y amparar a la población del término y sus rebaños en caso de peligro. Por ello, este gran recinto-refugio lleva el nombre de albacar, del árabe albaqar que tiene el significado de «los bueyes», sin duda relacionado con la función de refugio desempañada por este tipo de fortificación. Tales albacares se ven todavía bien conservados en Pego, Gallinera, Planes, Castell de Castells, etc... Las dimensiones son grandes, pues se pueden considerar como bastante representativos unos 150 a $200 \mathrm{~m}$. sobre 20 a 40 de anchura máxima, con lo que se encierran unas áreas comprendidas generalmente entre 3000 y $6000 \mathrm{~m} 2$. No insisto mucho sobre esta estructura particular del castillo-albacar bien estudiada en otras zonas de la región valenciana (18).

Quisiera en cambio hacer resaltar otro carácter importante de los castillos musulmanes de la zona, el de castillo-poblado. En determinados casos, como en el de Pop, encima de la montaña del Peñón que domina al valle de Laguart por una parte y al antiguo Valle de Pop, con Murla y Benichembla por otra, no se ve en la actualidad ningún resto de fortificación, pero la abundante cerámica esparcida en el suelo atestigua una importante ocupación del lugar en época islámica. En varios de los sitios que fueron ocupados por un castillo musulmán, los vestigios cerámicos, por su abundancia y la extensa área en la que se encuentran, revelan mucho mejor la antigua importancia del yacimiento que los pobres restos de unas construcciones casi desaparecidas. Se pueden citar como ejemplos, además de Pop donde no hay más vestigios que los cerámicos, los de Alaguar (o castell de las Atzavaras, cerca de Campell y Fontilles); Olocaiba (en Pedreguer), Jalón (o castell de Aixa), Serrella (cerca de Bañeres) y Almizra (cerca de Campo de Mirra). Por otra parte, en la mayoría de los castillos que conservan restos arquitectónicos mảs importantes, se encuentran también vestigios cerámicos, muchas veces fuera del actual recinto, y bastante abundantes para probar la existencia de una población cerca del castillo. Los

(18) Sobre al castillo-albacar, véase A. BAZZANA, “Albacar': la fonction refuge dans le château hispano-musulman de la région valencienne», en: Châteaux et peuplements en Europe occidentale du $\mathrm{X}^{e}$ au XVIII siècle, Premières journées internationales d'Histoire du Centr culturel de l'abbaye de Flaran, 20-22 sept. 1979, Auch, 1980, pp. 192-197, y el artículo citado en la nota 10. 
ejemplos de Castell de Castell y Tárbena son al respecto muy interesantes, y en el primero la presencia de un lugar habitado inmediato a los restos de edificaciones que constituyen el actual castillo, parece confirmada por un documento de 1290 que habla de la «villa o arrabal» de dicho castillo (19).

Estos hechos explican sin duda la relativa frecuencia con que las fuentes del siglo XIII utilizan la expresión «castillo y villa» (castrum et villa) al referirse a varios de los husun recién conquistados, cuando no consta la existencia de ninguna «villa» en el término, donde las fuentes medievales sólo mencionan unas alquerías. Ello ocurre por ejemplo en Pop, Alaguar y Jalón, Alcalá y Gallinera, Perpunchent, Gartx, para los que se alude a unas villas que no pueden corresponder sino al mismo castillo o su arrabal (20). A veces, no se separaron el castillo y la villa después de la conquista cristiana, y la estructura actual de pueblos como Planes o Guadalest puede darnos una idea de lo que debía ser el aspecto de estos pueblos agrupados alrededor de su castillo o albacar. Arqueológicamente, se puede estudiar una estructura parecida en el antiguo castillo de Gartx o Gargio, situado en el têrmino municipal de Bolulla, y a 2'5 $\mathrm{km}$ al nor-noroeste de la población actual, en la falda de una montaña dominada por una peña impresionante. Se ven todavía bastante bien los restos de los tres recintos que definían tres partes distintas: el castillo propiamente dicho, pequeño y que parece muy reformado en época cristiana, el albacar, y una extensa población o villa, mencionaa en los documentos escritos (21). Los muros son de piedra apenas aparejada, con poco mortero, y de construcción muy débil. Los restos que quedan son muy pobres, y no hay ningún vestigio de habitación, pero la cerámica se encuentra en abundancia, como en los demás yacimientos mencionados más arriba.

$\mathrm{El}$ abandono de estas villas musulmanas durante el siglo XIII debe sin duda relacionarse principalmente con las sublevaciones

(19) El documento es la venta del castillo por el rey a Bernardo de Sarriá, en Archivo del Reino de Valencia, Real 614, fol. $92 \mathrm{v}$.

(20) Archivo de la Corona de Aragón, Reg. Canc. $n^{\circ} 9$, fol. 39 r. y v. del 19 de sept. de 1257 (Alaguar, Jalón y Pop); id., Reg. 16, fol. 193 r., del l de mayo de 1270 (Gallinera y Al. calá); Id., Reg. 19, fol, 116 r., del 12 de junio de 1273, y Archivo Histórico Nacional, Mon. tesa, perg. 116 T., del 18 de marzo 1260 (Perpunchent).

(21) "Castrum et villam de Gargio", en Archivo de la Corona de Aragón, Reg. Canc. n" 14, fol. 88, del 26 de abril de 1267. 


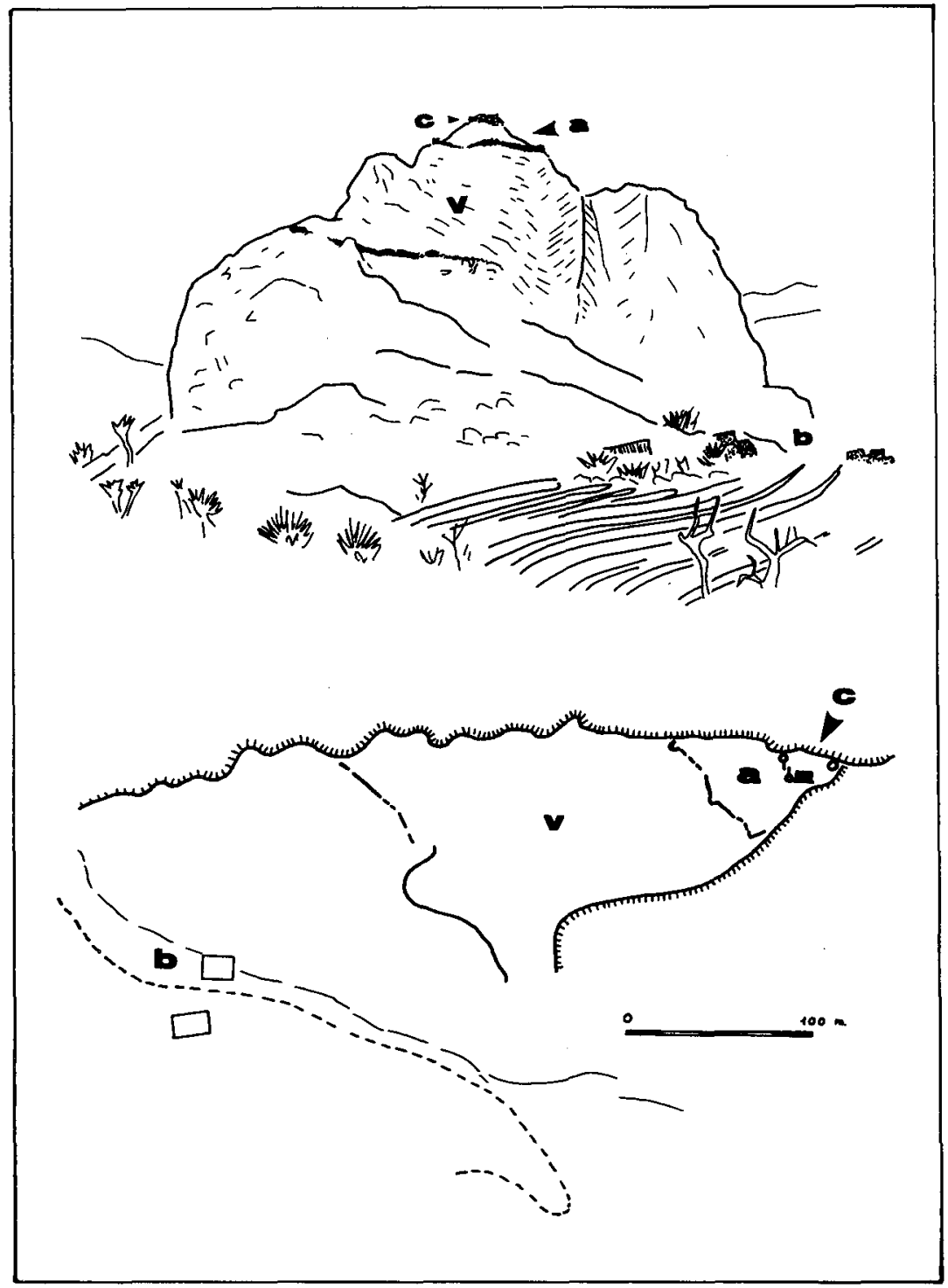

\section{Castillo de Gartx}

Situación de los tres recintos de la peña de Gartx, têrmino municipal de Bolulla (según fotografía), y plano esquemático de los mismos. El antiguo castrum presenta tres partes distintas: castell (c), albacar (a) y villa (v). En b, corrales modernos, al pie de la peña, a ambos lados del camino que lleva a Bolulla. 
sarracenas de la época. Hay prueba documental de la destrucción voluntaria, por parte de los cristianos, de algunos de estos castillospoblados de altura (22). En la mayor parte de los casos, sólo subsistió la parte central, la más alta, utilizada como castillo señorial, mientras la población musulmana solo permaneció en las alquerías del término. Cuando hubo creación de una villa de población cristiana, esta se asentó casi siempre en el llano, o en la parte baja del término, como ocurrió en Pego, Tárbena, Penáguila donde las poblas de colonización se instalaron bastante lejos del antiguo castillo musulmán. Por ello, muchos de los primitivos castillos perdieron toda importancia, y a veces desaparecieron casi completamente de la historia y de la geografía humana de la región, conservándose solamente algunos indicios toponímicos de la antigua presencia de un castillo (23).

(22) Sanchet en 1270 (véase la referencia documental en el apéndice, al final del artículo), Alaguar en 1284 (Archivo de la Corona de Aragón, Reg. Canc. ${ }^{\circ} 46$, fol. 105 v.)

(23) Se pueden dar como ejemplos la fuente de Gartx, cerca del castillo del mismo nombre, las montañas de Segarria y del Ocaibe, que han conservado los nombres de los castillos de Segarria y Olocaiba; en Bañeres, el lugar donde estuvo emplazado el Castillo de Serrella es conocido todavia bajo el nombre de "Castell de Serrella». Los nombres de los desaparecidos castillos de Sanchet y Alarch corresponden todavía a dos partidas rurales del término de Benimantell (partida de Sanchet y barranco del Arch). 
Castillos desaparecidos del Norte de la provincia de Alicante.

Se dan a continuaciọn, para cada castillo, un análisis de los documentos más significativos, y un breve comentario sobre estos y la posible situación del yacimiento.

\section{ALARCH y SANCHET}

- Crónica de Jaume I, par. 349 (1244, marzo, 3): Alarc viene citado en la lista de los cas. tillos que forman la frontera meridional del reino de Valencia en el tratado de Almizra.

- Rep., nº 0423 (1249, julio, 20): El término de Sanxet aparece como uno de los que lindan con la alquería de Liriet.

- A.C.A., Reg. Canc. 16, fol. fol. 198 v., y A.R.V., Real 614, fol. 126 v. (1270, junio. 26): El rey Jaime I concede para 5 años a $R$. de Balbes el castrum de Sanchet, y la alquería y los têrminos del de Alarch, cuya destrucción ha decidido. Tendrá que guardar el castillo, cobrando sus rentas y pagando al rey 600 sueldos anuales.

- A.C.A., Reg. Canc. 16, fol. 205 (1270, agosto, 14): El mismo da en feudo, a costumbre de Barcelona, al miles Berenguer de Lacera, alcaide de Penaguila, los castra, villas y alquerías de Alarch y Sanchét. Destruirá uno de los dos castillos, y mantendrá el otro en buen estado.

- A.C.A., Reg. Canc. 23, fol. 41 (1275, diciembre, 13): Al empezar la sublevación de los musulmanes valencianos, el rey ordena a B. de Lacera que guarde bien los castillos de Alarch y Sanchet.

- A.C.A., Reg. Canc. 22, fol. 107 v. (1278, sept., 25): La aljama de Alarch aparece en la lista de las comunidades musulmanas que deben al rey cierta cantidad de dinero por las cartas que les ha otorgado después de la sublevación de 1275-1277.

- A.R.V., Real 614, fol. 126 v. (1341, agosto, 30): Antonio de Lacera, hijo y heredero de Jaime de Lacera, miles, vecino de Guadalest, vende al infante Pedro conde de Ribagorza, del "castro seu fortitudine vocata Sanchet", que tiene en feudo del rey. Se dan como lindes los términos de los castillos de Polop, Aljubea, Guadalest y Alarch, y el término de Finestrat.

Los castillos y poblados de Alarch y Sanchet han desaparecido, y desconozco su situación exacta, si bien los topónimos han perdurado como nombres de partidas, en la zona meridional del término actual de Benimantell (Valle de Guadalest).

\section{ALMIZRA}

- Crónica de Jaume I, par. 343, (1244, marzo): Entrevista de los reyes de Castilla y Ara. gón en Almizra. Jaime I ofrece a Alfonso X establecerse en "lo castell d'Almiçre e la vila", pero este prefiere sentar sus tiendas «defora, al peu del pug d'Almiçra».

- A.C.A., Reg. Canc. 10, fol. 82 (1258, junio, 28): Donación a Jimeno Pérez de Foces de un terreno en la alquería de Benixamen, del término de Almizra, para construir unas casas para establecer musulmanes.

- A.C.A., Reg. Canc. 13, fol. 174 (1264, mayo, 17): El rey concede a Arnaldo de Montsó y sus herederos el castillo de Almizra "cum turribus et aliis bastimentis», debiendo tener en el "duas gaytas duplices». El rey le pagará, para la custodia y las obras, 300 sueldos anuales, consignadas sobre las rentas del término, que siguen perteneciendo al rey.

- A.C.A., Reg. Canc. 16, fol. 254 r. (1271, junio, 14): El rey da a Jaime de Linares unas casas «in villa Almizrani», y tierras en el término.

- A.C.A., Reg. Canc. 44, fol. 180 (1280, abril, 11): El rey confirma a los pobladores de Biar ias heredades y los términos de dicho castillo y de Almizra, Beniyama, Negret y Benizamaya, segun las asignaciones que les ha hecho Jaime de Linares, partidor de las heredades del reino de Valencia.

- A.C.A., Reg. Canc. 100, fol. 142 y 170 (1294, sept. 24 y oct. 15): El rey, informado de que Alfonso Pérez ha comprado el castillo o lugar (castrum seu lucum) llamado de Almiçerano a los herederos de Arnaldo de Montso, y otras heredades en el mismo lugar a va- 
rios hombres de Biar, protesta de sus derechos sobre dicho castillo, y manda se suspencta cl efecto de la venta.

- A.R.V., Real 611 , fol. 108 (1298, enero, 18): El rey concede a Lorenzo de Scals, vero nés, y a sus herederos, el castillo de Almizra, que tendrá en adelante como castellano o al caide.

- A.C.A., Reg. Canc. 204-205, fol. 146 (1307, marzo-abril): El rey concede en feudo a costumbre de Barcelona a Alfonso Pérez el castillo de Almizra. Este se compromete a realizar las obras necesarias en dicho castillo.

En el cerro que domina la actual población de Campo de Mirra, se ven todavía los restos de una importante población, atestiguada por la abundante cerámica medieval, y de un pequeño castillo, probablemente de fábrica cristiana. La despoblación de la villa asentada en el pug o puig debio de ser consecutiva a la sublevación musulmana de $1275 \cdot 1277$. Al pare. cer, el lugar quedó abandonado, y las tierras de término repartidas entré los pobladores de Biar, hasta el intento de ocupación señorial por Alfonso Pérez, que consigue por fín que el rey le conceda el castillo. Benejama no era inicialmente sino una alquería del término.

\section{ALJUBEA}

- A.C.A.. Reg. Canc. 15, fol. 9 v. (1265, diciembre, 27): El rey da a Lope Sánchez de Vergais la alquería de Chenli, colindante con Polop, Callosa, y el castrum de Aljubea.

- A.C.A.. Reg. Canc. 22, fol. 107 v. (1278, sept., 25): Aparece una aljama de Aljubea en la lista de las aljamas musulmanas que deben al rey cantidades de dinero por las cartas que les ha otorgado al fin de la sublevación de 1275-1277.

Este castillo de Aljubea, que parece haber sido situado entre los actuales términos de Polop. Finestrat y Guadalest, vuelve a aparecer en documentos del siglo XIV (Donación de 1322 en A.R.V., Real 614, fol. 127, y doc. del año 1341, del mismo registro, en el que se da el término de Aljubea como colindante con el de Sanchet, partida actual situada en la parte meriodional del término municipal de Benimantell, del valle de Guadalest, que corresponde a un antiguo castillo).

\section{BERDIA}

- A.C.A., Reg. Canc. 14, fol. 17 v. (1263, mayo, 9): El rey consigna a A. de Monsó, baile ultra el Jucar, una cantidad sobre los réditos de los castillos de Benicadell y Berdía.

- A.C.A., Reg. Canc. 13, fol. 176 (1264, mayo, 23): Comanda de la custodia del castillo de Bergia a Pedro Blasch, con 6 hombres. Su salario de 900 sueldos se consigna sobre los ré. ditos de Gallinera y Guadalest.

- A.C.A., Reg. Canc. 19. fol. 63 v. (1273, oct., 19): Defínición de cuentas de Pedro Diego, relativas a su administración de los réditos de los castra de Berdia y Altea durante 6 meses.

- A.C.A., Reg. 20, fol. 326, y Reg. 23, fol. 59 v. (1276, febrero, 28): Cuentas de Pedro Diego, alcaide del castillo de Verdia, durante dos años. De las rentas del término, se deduce el salario para los hombres que lo guardan (8, y dos perros), y el diezmo para el obispo de Valencia.

- A.C.A., Reg. 80 , fol. 85 r. (1289, noviembre, 4): Fl rey pide a B. de Libiano, baile de las mont añas de los musulmanes del reino de Valencia. que le informe sobre el valor de los léditos de varios lugares, entre ellos el "lugar de Verdia con su término, o sea Callosan.

En la cumbre de la sierra de Bernia, todavía se pueden ver los restos de una torre que correspondería a este "castillo de Bernia» (véase J. MESTRE PALACIO, Alcalalí, Alicante, 1970. p. 142).

\section{CHEROLES O ỲURULAS}

- A.C.A., Perg. di Jaime I, nº 1374 (1244 o 1245, abril): En el "pacto de Alcalá», concertado entre Jaime I y el jefe musulman al-Azraq. un hisn o castrum de Djurûlash figura entre los 8 castillos tenidos por este último. 
- A.C.A., Reg. 8, fol. 36 r. (1257, noviembre, 24): Peyta de 600 besantes exigida por el rey de los musulmanes de Seta y Cerolles.

- A.C.A., Reg. Canc. 10, fol. 103 v. (1258, mayo, 22): Arriendo a Gonzalo Ferrando durante dos años de los réditos reales de los castra a Seta y Cherolis.

- A.C.A., Reg. 10, fol. 103 (1268, junio, 15): Donación al mismo de 12 jovadas de tierra. de los cuales 8 están en el término de Cherolas, en el lugar llamado Tollo (situado inter Serellam et Fontavaram), y las demás en Seta.

- A.C.A., Reg. 16, fol. 211 (1270, septiembre, 6): El rey da a Dona Bella y su hijo Roger (Roger de Lauria) el "castrum de Seta et Cherolles".

No conozco documentación posterior sobre este castillo, situado cerca de Tollos, y cuyo término lindaba con el de Seta, y al parecer se confundia con este último. Se considera generalmente que se trata del despoblado de la Careola o Cairola, situado a $2 \mathrm{~km}$ al oeste del lugar de Beniaya, del valle de Alcala. Sin embargo, este poblado parece haber pertenecido mas normalmente a dicho valle, y forma parte de una unidad geográfica distinta a la del valle de Seta. Además, cabría explicar por que su término fue segregado de la unidad inicial, constituida en señorio para Roger de Lauria y su madre. Por fin, la topografía de la Careola de Beniaya corresponde mal al esquema acostumbrado de los husun o castra musul manes de Valencia.

\section{MARIOLA}

- A.R.V., Real 614, fol. 236 rv. (1256, marzo, 11): En la "carta puebla" de Bocairente, el rey especifica que los pobladores se repartirán, además del término de dicho castillo y villa, los de los dos castra de Agres y de Mariola.

A unos $3 \mathrm{~km}$. al sur de Alfafara, en termino de Bocairente y entre esta ciudad y Alcoy, se encuentran los restos del castillo de Mariola (información proporcionada por José María SEGURA MARTl). El lugar se encuentra en la provincia de Valencia, pero es toda la zona montañosa en el limite de Valencia y Alicante. la que ha conservado el topónimo Mariola.

\section{SEGARRIA}

- A.C.A., Reg. Canc. 10, fol. 20 (1257, septiembre, 24): Aprobación de cuentas a Carroz concernientes a su administración «de castris et villis» de Denia, Segarria, Alaguar, Pop, Xalón. Olocaiba y Polop.

- A.C.A., Reg. Canc. 10, fol. 64 v. (1258, abril, 30): El rey reconoce deber a Sancho de Corella 4.280 sueldos por ciertos abastecimientos, y por la guardia de los castillos de Denia y Segarria. Deberá tener 15 hombres en el primero, y 10 en el otro.

- A.C.A., Reg. Canc. 78, fol. 14, y A.R.V., Real 614, fol. 92 r. (1288, octubre, 5): El rey concede en feudo, a costumbre de Barcelona: «la fortaleza de Segarria en la que solía haber un castillo" (fortitudinem de Segarria in qua consuevit esse castrum).

En el lugar del termino de Benimelí llamado la "Caireta del rey moro", formando como un rellano rocoso defendido por un impresionante acantilado en la vertiente noroeste de la sierra de Segarria, se puede ver el magnífico refugio natural que constituia el castrum de segarria, centro de un termino que incluía a los actuales municipios de Sanet y Negrals, Benimeli, Rafol de Almunia, Sagra. Parece que este castrum, en el que los únicos acondicionamientos humanos era una gran cisterna y unos muros que protegian, en sus dos extremidades, los dos posibles accesos, sólo tuvo una ocupación militar cristiana durante los períodos de crisis (primera sublevación de Al-Azraq, y sublevación musulmana de 1275 . 1277), hasta que fue «señorializado» en el año 1288.

\section{SERRA (de Finestrat), TORRES y la MOLA}

- Crónica de Jaume I, par 349 (1244, marzo, 3): En la lista de los lugares fronterizos que el tratado de Almizra deja a Aragón, se mencionan ala Mola que es prop de Agnes (sin duda Aguas de Busot)m, Torres y Finestrat. 
- J. TORRES FONTES, Col. de doc. para la hist. del reino de Murcia, II, documentos del siglo XIII, Murcia, 1969, doc. V (1244, sept., 30): El ex-rey musulman de Valencia. Zeyt abu Zeyt, vende a la Orden de Santiago los castillos de Tibi, Orcheta y Torres.

- Crónica de Jaume 1, par. 361 (año 1247): la primera sublevación de al-Azraq empieza por la toma por este de los tres castillos de Gallinera, Serra y Pego, que estaban en manos del rey.

- A.C.A., Reg. Canc. 10, fol. 77 (1258, junio, 16): El rey da a los musulmanes l'eviçino y su hijo Çaat los castra et villas de Orcheta, Finestrat y Torres.

- A.C.A., Reg. Canc. 16. fol. 205 v (1270, agosto, 20): El rey da a Berenguela Alfonso en libre y franco alodio los castillos y villas de Orcheta, Serra, Mola. Finestrat y Torres. en la misma forma que los tuvieron Tevicino, su hijo Çaat y demás musulmanes.

- A.C.A., Reg. Canc. 37, fol. 13 r. (1271, marzo, 19): El infante Pedro confirma a Beren. guela Alfonso los castillos de Segorbe, Onda, Mogente y Finestrat, ket fortitudinem quod vo. catur Serra».

- A.C.A., Reg. Canc. 16, fol. 258 (1271, abril, 9): Berenguela Alfonso ha entregado a la Orden de Santiago los castillos de Orcheta y Torres.

- A.C.A., Reg. Canc. 21, fol. 43 v. (1272, junio, 21): El rey embarga a favor de Pedro Diego los reditos de "Castrum nostrum de Serra et alcherias de Serra et de Fenestrat".

- A.C.A., Reg. Canc. 22, fol. 47 (1276, julio, 6): Computo de cuentas por la retención que hizo Eximen Pérez de Oris, en tiempo de Berenguela Alfonso y por clla, de los castillos de Orcheta, Serra, Mola y Carmoxen.

- Crónica de Jaurne I, par. 555 (inicios de 1276): Sublevación del alcaide musulman Ibrahim "que havia bastit un castell que nos haviem enderrocat ja peça havia, lo qual ha nom Serra de Finestrat".

- A.C.A., Reg. 47, fol. 55 v. (1283), octubre, 7): Notificación a los oficiales reales de ha. ber sido suprimidos ciertos derechos reales en los lugares de Pedro Ferrando. hermano del rey, entre los cuales Sierra Orcheta y Torres.

- A.C.A., Reg. Canc. 75, fol. 51 (1288, enero, 24): El rey da a su tio Pedro Ferrando "castrum vocatum Finestrat, sive Serram de Finestrat".

- A.R.V., Real 614, fol. 127 r. (1332, octubre, 15): Documento en el que se menciona la donación hecha por Bernardo de Sarriá al infante Pedro de varios lugares, entre ellos: «castrum de Serra de finestrat el locum de Finestrat».

De los citados documentos, se puede deducir que, en la zona que ocupan actualmente los têrminos municipales de Finestrat, Orcheta y Villajoyosa (esta última ciudad fundad en fecha más tardia), existían varios lugares habitados o castillos actualmente desaparecidos. El castillo de Serra se encuentra generalmente asociado a Finestrat, lugar que no tiene siempre la categoría de castillo. Por lo tanto. podemos suponer que se trataba de un antiguo castrum, centro de la zona que corresponde al término actual de Finestrat, sí bien parece que esta última población ya era el lugar habitado más importante de dicho término. En cuanto a Torres, subsiste el topónimo como nombre de una partida o un barrio de Villajoyo. sa, ciudad de creación cristiana, al nordeste de la población. La Mola debía ser un refugio natural en los lindes de Villajoyosa y Orcheta por una parte y Aguas de Busot por otra (no he visitado personalmente esa zona).

\section{SERRELLA}

- A.C.A., Cartas Reales de Jaime I, Caja 2, Extra series n 70 (1249, octubre, 13): El rey da en alodio a Jofre de Loaysa «castrum et villam de Bigneras, et castrum et villam de Serrella".

El documento es una copia de época moderna, pero tanto la donación a Jofre de Loaysa como la existencia, a poca distancia de Bañeres, y formando con esta última población una misma entidad y un termino único, es confirmada por la documentación posterior y por la evidencia arqueológica. Los registros de Cancillería de la Corona de Aragón conservan algunos documentos que hacen referencia a litigios sobre delimitación de términos entre el señor de Serrella y Bañeres por una parte, y las autoridades municipales de Bocairente por otra 
(véase el largo comentario a un documento de 1265 sobre esta materia en un artículo del P. Burns, "Los límites interiores de Valencia en un artículo del P. Burns, "Los límites interiores de Valencia de la Reconquista», Medievalia (Univ. Autónoma de Barcelona), 1, 1980). El castrum de Serrella ocupaba una altura situada a un kilometro de Bañeres y al sur de la población, frente a esta en la otra orilla del Vinalopó. El lugar es conocido todavía bajo el nombre de Castell de Serrella, y se ven algunos restos de fortificación, y mucha cerámica en el suelo. Cabe suponer que Serrella era el establecimiento primitivo, y Bañeres una antigua alquería, pero que había cobrado bastante importancia para ser designado como castrum en la documentación de la época de la conquista. sin embargo, el actual castillo de Bañeres parece haber sido edificado en época cristiana. 